\title{
Benefit of Preanesthetic Consultation to Decrease the Level of Pre-operative Anxiety and Increase Post-operative Satisfaction
}

\author{
Clara F. Mendoza-Rosales*, Hilda A. Llanes-Garza, Roberto M. García-Torres, Juan F. González-Juárez \\ and Dionisio Palacios Ríos
}

Department of Anesthesiology, School of Medicine, "Dr. José Eleuterio González" University Hospital, Autonomous University of Nuevo Leon, NL, Mexico

\begin{abstract}
Objective: To demonstrate the level of pre-operative anxiety between patients who had the preanesthetic assessment performend prior to the day of the surgery in the preanesthetic consultation vs. the ones who had it performed in the presurgical area the day of the surgery. Materials and Methods: An Amsterdam Preoperative Anxiety and Information Scale assessment (APAIS) was performed among patients scheduled for elective surgery, identifying in the preoperative area those who attended the preanesthetic consultation for prior preanesthetic assessment and the one who doesn't, and after 2 to 24 hours postanesthesia, the patient satisfaction were evaluated through a questionnaire about the anesthesiologist-patient relationship, the, anesthetic management, and the postanesthetic satisfaction. Results: From 64 patients, the APAIS revealed that $40.60 \%$ evaluated in the preanesthetic consultation did not present pre-operative anxiety, and $75 \%$ of those who did not attend the preanesthetic consultation presented pre-operative anxiety. $60.93 \%$ of the patients were female. $42.19 \%$ of patients were undergoing major surgery, $54.68 \%$ of patients had an anesthetic risk according to the American Society of Anesthesiologists scale. The specialty with the fewest previous preanesthetic evaluations was general surgery (64.29\%). The most used anesthetic technique was general balanced anesthesia (30.16\%). 25\% of the patients with previous evaluations had predictive data of difficult airway. The highest score on anesthesiologist-patient attention was nine, mainly those previously assessed in the consultation. Conclusion: Previous preanesthetic consultation decreases pre-operative anxiety. More than half of the population felt satisfied with the anesthesia.
\end{abstract}

Key words: Pre-operative anxiety. Preanesthetic evaluation. Postanesthesia satisfaction. Anesthesiologist-patient relationship. The amsterdam preoperative anxiety and information scale.

\section{Introduction}

According to the World Health Organization, $20 \%$ of the world's population will endure some type of anxiety disorder at some point in their lives'.

Anxiety involves an experience with various degrees of uncertainty, agitation, and dread. People present physical signs such as tachycardia, nausea, vomiting, muscle twitching, abdominal pain, sweating, difficulty swallowing, and other symptoms, which may be confused with those of other pathologies, thus delaying a precise diagnosis ${ }^{2}$. Patient referral to a preanesthetic consultation before the day of the surgery helps in identifying those patients with anxiety secondary to surgery. Among other benefits, the objective of a preanesthetic evaluation is to reduce perioperative-perianesthesia morbidity and mortality $^{3}$, three delays and

\section{Correspondence:}

Clara Fernanda Mendoza-Rosales

E-mail: cfernandamendoza@gmail.com
Available online: 18-01-2019

Medicina Universitaria. 2018;20(4):156-160

www.medicinauniversitaria.org CC BY-NC-ND license (http://creativecommons.org/licenses/by-nc-nd/4.0/) 
cancellations on the day of the surgery, and increase perioperative efficacy and warmth ${ }^{4}$.

This study assessed pre-operative anxiety with the support of the APAIS survey, which according to previous studies, helps to identify pre-operative anxiety levels and the patients' need for information ${ }^{5}$. It includes six questions which the patient must answer using a 5-point scale. Of these, four are questions evaluating anxiety regarding anesthesia and intervention, and two are questions regarding the demand for information about anesthesia and the surgery (Annex 1$)^{6}$.

The objective of this paper was to evaluate the level of anxiety of all the patients who were at the pre-operative area of the hospital, scheduled for elective surgery. They were divided into two groups: patients with a preanesthetic evaluation previous to the day of the surgery, and patients without a previous preanesthetic evaluation.

The level of satisfaction on the anesthesiologist-patient relationship was assessed after finalizing recovery at the post-operative area through a questionnaire consisting of six questions (Annex 2).

\section{Materials and Methods}

Patients of both genders between 18 and 70 years of age, without a history of anxiety disorders, classified by the American Society of Anesthesiologists (ASA) as Class 1 and 2 based on their physical state (according to their risk of anesthesia), scheduled for elective surgery at the "Dr. José Eleuterio González" University Hospital, and identified in the pre-operative area. Patients who did not have previous evaluations had one performed right then and there providing them with the same information that the other group received at consultation. For those who attended a previous preanesthetic evaluation, this was not necessary.

Subsequently, under the authorization code AN170003 granted by the Research and Ethics Committee at the same university, the candidates were made aware of their participation in the research work and were informed of the application of a survey. Regarding the gathering of data in the previously elaborated sheets containing patient data, type of surgical procedure, and the APAIS survey, we evaluated anxiety and relation to anesthesia and the procedure through for questions, while two questions referred to the demand for information by the patient. After 2-24 $\mathrm{h}$ postanesthesia, patient satisfaction was correlated through six basic and general questions regarding the patient-anesthesiologist relationship, anesthetic management, and

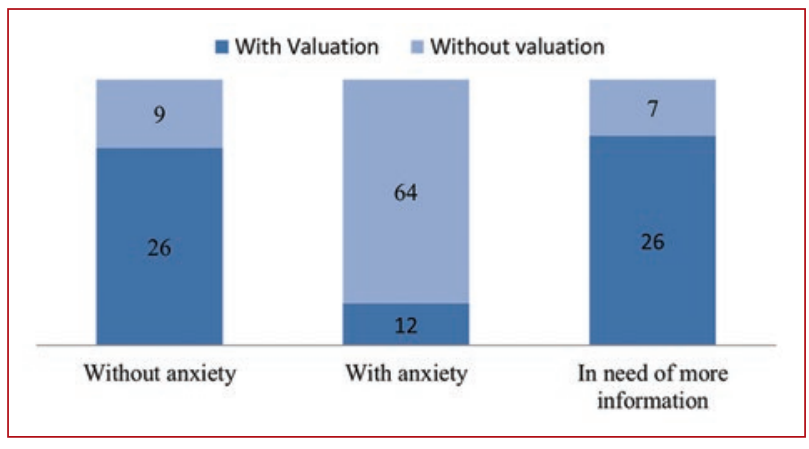

Figure 1. Relationship of patients according to the Amsterdam Preoperative Anxiety and Information Scale assessment scale.

whether the information previously provided by the physician was enough.

A statistical analysis was conducted using Microsoft Excel, which was designed keeping in mind all the variables above and comprising all the obtained data.

Calculations for the sample size were performed using a comparison of proportions formula for the hypothesis, considering an expected value of the patient percentage with the condition in a P1 of $30 \%$, an expected value of the patient percentage without the condition in a Q1 of $70 \%$, an expected value of the patient percentage with the condition in a P2 of $70 \%$, an expected value of the patient percentage without the condition in a Q2 of $30 \%$, with a power of $95 \%$, and a significance of $95 \%$. Obtained results were of 29 patients per group.

For qualitative variables, the Chi-square test of homogeneity and the Fisher exact test were used. A value of $p<0.05$ (two-tailed) was considered as statistically significant. We used the software SPSS Statistics version 20 (IBM, Armonk, NY, USA) for Windows 7.

\section{Results}

A total of 64 patients were included in this study during February 2017, concluding with the following:

- Pre-operative anxiety: (Fig. 1)

- Demographic variables.

We studied a population with a slight female majority $(60.93 \%)$, and with a wide range of ages, going from young adults up to older adults, with an average age of 42.5 years (Fig. 2).

- Dependent variables of the surgery and anesthesia. It was observed that the majority of patients were programmed and arrived at the pre-operative area fomajor surgeries without a previous preanesthetic 


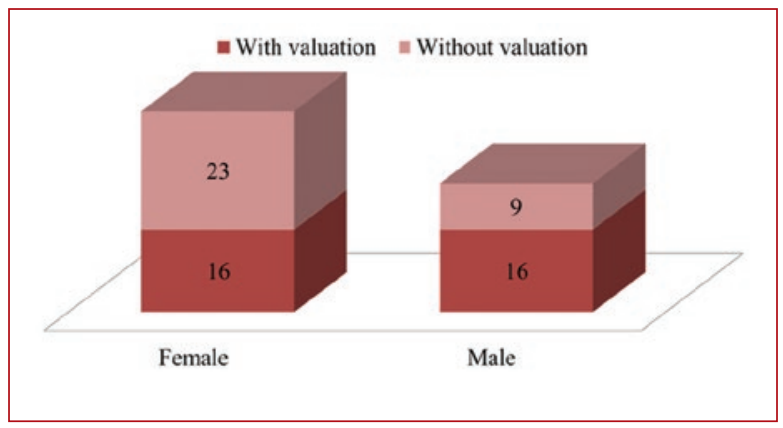

Figure 2. Total patients according to gender who had an evaluation without preanesthetic assessment.

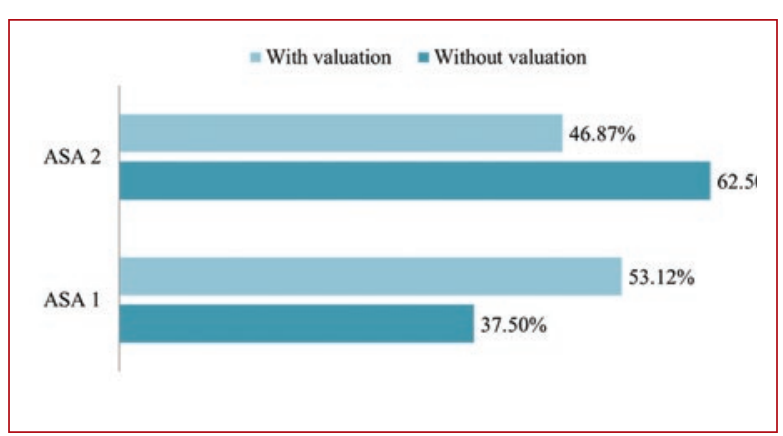

Figure 3. American Society of Anesthesiologists of each group.

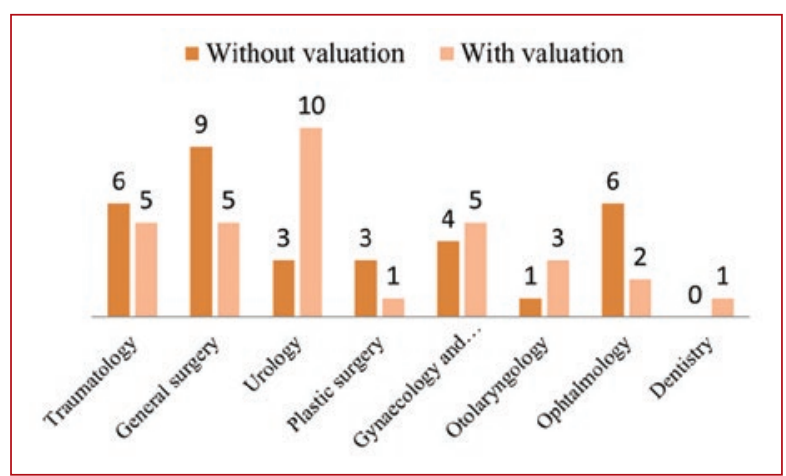

Figure 4. Surgical specialties.

evaluation. Also, that at the preanesthetic consultation evaluations are conducted in more patients for minor surgeries, fact that should be different.

Our findings showed that the patients which ought to have a previous evaluation about their ASA classification did not have one (Fig. 3). And the surgical specialities which surgical procedures almost daily, fail to send their patient to preanesthetic consultation (Fig. 4).

Moreover, it was possible to observe that patients without the previous experience of a surgery, and the stress that this entails, were the ones who did not have

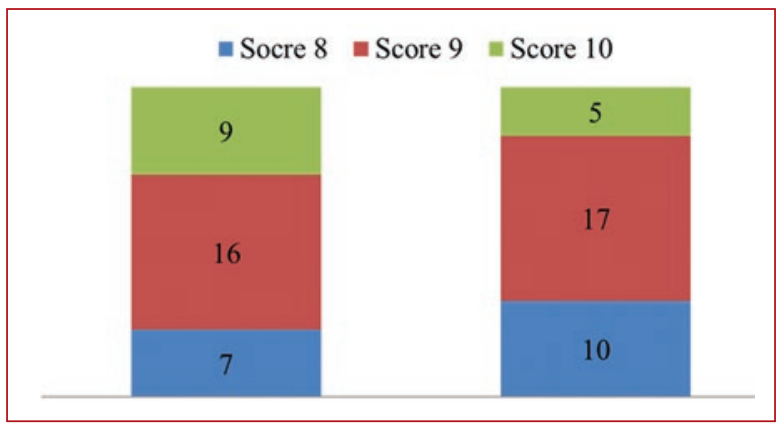

Figure 5. Patient-anesthesiologist relationship grading.

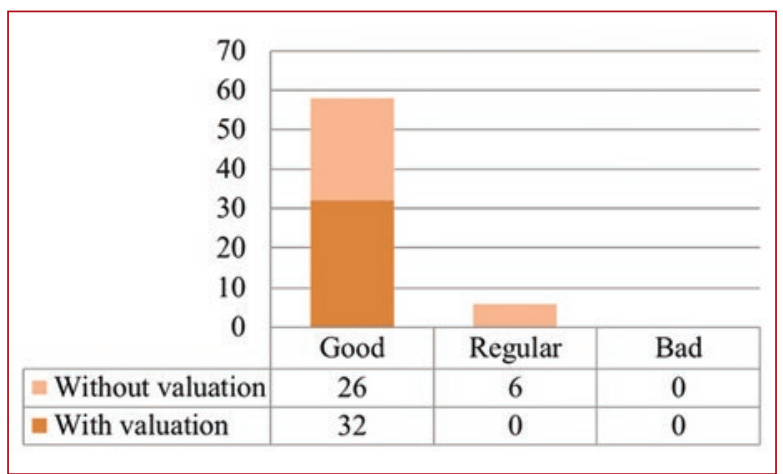

Figure 6. Satisfaction level according to the patient group.

a preanesthetic evaluation at a preanesthetic consultation. They were also the ones who had the most questions on the day of the surgery.

The most utilized anesthetic technique was general balanced anesthesia (30.16\%), being predominant among those patients without a preanesthetic evaluation (17.18\%).

In patients with a previous preanesthetic evaluation, timely detection of probable difficult airways was done in $12.5 \%$, highly important information for the anesthesiologist, since it helps them prepare and take necessary measures before applying any type of anesthesia.

In conclusion, the attention and experience of the patients with anesthesia were favorable, rating the patient-anesthesiologist relationship with a 9 (Figs. 5 and 6).

\section{Discussion}

Any person who is admitted to a hospital presents anguish and anxiety, for the sole reason of being sick, even more so when they go into undergo a surgical procedure ${ }^{7}$. Thus, it is very important that patients are given the necessary time to ask questions about the procedure, and given complete information and an 
adequate patient-anesthesiologist relationship. All of this can be achieved by attending a preanesthetic consultation.

The results of our study demonstrated that a large majority of the patients who underwent elective surgery at the "Dr. José Eleuterio González" University Hospital and who were not referred to a previous preanesthetic consultation for an evaluation, presented anxiety $(75 \%)$. Similarly, high levels of anxiety were shown in the studies conducted by Doñate et al. ${ }^{8}$, Yoshinobu et al., ${ }^{9}$ Valenzuela et al.. ${ }^{10}$ and Masood et al. ${ }^{11}$ concurring that this is due to a lack of information and knowledge that the patients receive before the surgical anesthetic procedure.

The lack of knowledge about pre-operative anxiety is a frequent event, seldom evaluated in patients who will undergo a surgical procedure, which by itself is a major event, one which generates different levels of anxiety. This is shown to decrease if the patient is previously sent to an evaluation.

Evaluation at preanesthetic consultation is an important variable in which several authors concur that it functions as a protecting factor concerning anxiety. In our study, this finding was significant. It reduced the anxiety score ( 1 vs. $2, p<0.001)$ at a statistically significant rate. We can argue this based on a study published by Yoshinobu et al., ${ }^{9}$ who found that those who received better preanesthetic information during their visit to the anesthesiologist showed reduced anxiety rates compared to those who did not receive said information; in addition, Valenzuela et $a .^{10}$ as well as Masood et al. ${ }^{11}$ reached the same conclusion.

Furthermore, having attended a preanesthetic consultation reduced the patient's need for more information about anesthesia on the day of the surgery and the incidence of adverse events during anesthesia and surgery, improved patient-anesthesiologist relationship, and provided a more pleasant psychological state for the patient.

Every day, there are a growing number of studies showing that presurgical psychological state, especially anxiety, affects postsurgical recovery. Another major factor which has been concluded in this and other studies is that females have a risk up to 5 times higher than males.

Concurring with other studies, we consider selecting the APAIS scale to have been a success, since it has proven to be a great tool for the evaluation of pre-operative anxiety due to its high reliability and reproducibility.

Without a doubt, the use of APAIS and the knowledge of the existence of this pre-operative psychological state helped us to discover the degree of anxiety of the patient promptly, which led to better quality in their care. It modified postsurgical recovery by reducing complications and avoiding an increase in post-operative care costs such as large doses of medications to induce analgesia.

This study allowed us to prove that a postanesthetic visit is a fundamental tool to identify adverse events in a timely manner and increase the general perception regarding patient-anesthesiologist rapport, as well as the general satisfaction with the anesthetic procedure.

Today, quality is a fundamental aspect in medical care, which was not taken into consideration for a long time yet has started coming up more and more. Moreover, we ought to put it in practice because the safety and satisfaction of the patients constitute the reason for being good physicians. ${ }^{11}$

The conclusion reached with this study is that at the University Hospital, there is a need to make physicians aware of the importance of referring patients to a preanesthetic consultation before the day of their surgical procedure. This has proven to reduce the level of pre-operative anxiety, provide timely identification of patients with a high risk of difficult airways, and strengthen patient-anesthesiologist rapport, as well as the right of the patients to receive complete and comprehensible information on the surgical procedure they will undergo its complications, alternatives, and benefits.

\section{Conflicts of interest}

There are no conflicts of interest between collaborators.

\section{Declaration of ethical responsibilities}

Protection of people and animals: All collaborators declare that no experiments were performed on humans or animals.

Data confidentiality: The authors of this work declare that we have strictly followed protocols on the publication of patient data.

Right to privacy and informed consent: We declare that no patient data appear in this article.

\section{References}

1. Carapia SA, Mejía TG, Nacif GL, Hernández ON. Efecto de la intervención psicológica sobre la ansiedad preoperatoria. Rev Mex Anest. 2011; 34:260-3.

2. Moreno CP, Calle PM. Detección y actuación en la ansiedad preoperatoria inmediata de la teoría a la práctica. Cir May Amb. 2015;20:74-8. 
3. Mena MR, Rodriguez ME. Valoración preanestésica. Importancia en el paciente quirúrgico. Rev Hosp Jua Mex. 2014;81:193-8.

4. Ham AK, Pardo MR. Ansiedad preoperatoria. Arch Inv Mat Inf. 2014;6:79-84

5. Moerman N, Dam FS, Muller MJ, Oosting H. The Amsterdam preoperative anxiety and information scale (APAIS). Anesth Analg. 1996;82:445-51.

6. Berth $\mathrm{H}$, Petrowski K, Balck F. The Amsterdam preoperative anxiety and information scale (APAIS)-the first trial of a German versión. Psychosoc Med. 2007:4:1-8.

7. Castellanos OA, Cervantes HE, Vásquez MP. Satisfacción anestésica como indicador de calidad de la atención médica en el paciente geriátrico. Rev Mex Anest. 2013;36 Supl 1:S250-55
8. Doñate MM, Litago CA, Monge SY, Martínez SR. Aspectos de información preoperatoria relacionada con la ansiedad del paciente programado para cirugía. Enferm Global. 2015;37:170-80.

9. Yoshinobu KL, Kakumu KL, Marçalo OL, et al. Surgery information reduces anxiety in the pre-operative period. Rev Hosp Clin Fac Med Sao Paulo. 2004;59:51-6.

10. Valenzuela MJ, Barrera SJ, Ornelas AJ. Ansiedad preoperatoria en procedimientos anestésicos. Cir Cir. 2010;78:151-6.

11. Masood J, Asim M, Sabih M, Zeeshan K. Preoperative anxiety before elective surgery. Neurosciences. 2007;12:145-8.

\section{Annex 1. The APAIS}

\begin{tabular}{|l|l|l|l|l|l} 
Statement & 1 absolutely no & 2 to some extent & 3 often & 4 A lot & 5 too much
\end{tabular}

I am worried about the anesthesia

The anesthesia is on my mind continually

I would like to know as much as possible about the anesthesia

I am worried about the procedure

The procedure is on my mind continually

I would like to know as much as possible about the procedure

APAIS: Amsterdam preoperative anxiety and information scale assessment
5 points or less
No anxiety
5-7 points
Does not require information
8-10 points
Requires more complete information
Max. 30 points
With anxiety

\section{Annex 2. Satisfaction levels}

Do you consider the information provided by the anesthesiologist before the intervention to be adequate?

Do you consider the explanation provided by the anesthesiologist to have reduced your concerns about anesthesia?

Are you satisfied with your anesthesiologist?

Were you satisfied with the anesthesia?

\begin{tabular}{|l|l|l|l|}
\hline & Good & Bad & Regular \\
\hline Your experience with anesthesia was & &
\end{tabular}

\section{\begin{tabular}{|l|l|l|l|l|l|l|l|l|l|}
1 & 2 & 3 & 4 & 5 & 6 & 7 & 8 & 9 & 10 Excellent \\
\hline
\end{tabular}}

What score would you give to the attention of the anesthesiologist with you? 